\title{
Evaluation of Safety Margin on Steel Truss Bridge After-Fracture State
}

\author{
San Yu Khaing \\ Professor \\ Department of Civil Engineering \\ Mandalay Technological University
}

Myanmar

\begin{abstract}
This paper presents fracture critical member identification of steel truss bridge by determining demand to capacity ratio of axial load and linear redundancy analysis of truss bridge. Bridge redundancy evaluation has become crucial in both designing new highway bridges and repairing or retrofitting old bridges after bridge collapses around the world in recent years. This study aimed to evaluate system redundancy of truss bridge after failure of one critical main truss member. Redundancy analysis is investigated through a case study of four spans continuous steel truss bridge. Finite element (FE) analysis was carried out using SAP 2000 software. In this paper, six cases of diagonal member removal are considered for redundancy analysis. Results from FE analysis showed that the effect of member removal is highest when the damaged truss diagonal member is near the support.
\end{abstract}

Key Words: Steel Truss, Redundancy Analysis, Demand to Capacity Ratio, Fracture Critical Member.

\section{INTRODUCTION}

Several recent catastrophic collapses have altered structural engineering community to the importance of designing structures with sufficient levels of structural redundancy and robustness to make them capable of withstanding local failures and retaining some levels of limited functionality. Aging of steel truss bridges is an ongoing problem in Myanmar,so maintenance of these bridges are essential to ensure the safety of the public. Removal of fracture critical members provides the location where special attention needs to be paid for maintenance of bridge.

Bridge redundancy is the capacity of a bridge superstructure to continue to carry load after the damage or failure of one of its members (NCHRP-406,1998). ${ }^{[3]}$ Redundancy is one of the most important factors to evaluate the safety of a bridge because bridge redundancy can define the structural redundancy level through bridge safety checking after a member damage occurs on one of its members. The objective of the research is to identify critical main truss member whose failure is expected to result in the collapse of the bridge or the inability of the bridge to perform its function. ${ }^{[1]}$

\section{LINEAR REDUNDANCY ANALYSIS}

Linear redundancy: The resistance of structure is evaluated through member-capacity checking of linear analysis results. No safety factors are used in calculation of $\mathrm{D} / \mathrm{C}$ ratio( $R$ value $)$. If any member gives $D / C$ ratio $(R$ value $) \geq 1$, that member is considered as failure.

In this method, the interaction equations(1) and (2)are used to determine member capacity. ${ }^{[2]}$

For $\frac{\mathrm{Pu}}{\emptyset \mathrm{Pn}} \geq 0.2$, the capacity ratio, $\mathrm{R}$ value is given as

$$
R=\frac{P u}{\emptyset P n}+\frac{8}{9}\left(\frac{M u 33}{\emptyset b M n 33}+\frac{M u 22}{\emptyset b M n 22}\right)
$$

For $\frac{\mathrm{Pu}}{\emptyset \mathrm{Pn}}<0.2$, the capacity ratio, $\mathrm{R}$ value is given as 


$$
R=\frac{P u}{2 \emptyset P n}+\left(\frac{M u 33}{\emptyset b M n 33}+\frac{M u 22}{\emptyset b M n 22}\right)
$$

If $\mathrm{P}_{\mathrm{u}}$ is tensile, $\emptyset=\emptyset t=0.9$ and if $\mathrm{P}_{\mathrm{u}}$ is compressive, $\varnothing=\emptyset c=0.85$ are used for calculation of nominal axial tensile strength and nominal axial compressive strength. In equation, $\mathrm{P}_{\mathrm{u}}, \mathrm{M}_{\mathrm{u} 33}$ and $\mathrm{M}_{\mathrm{u} 22}$ are factored axial force and factored major and minor moments in member. $\mathrm{P}_{\mathrm{n}}$ is nominal axial load strength and $\mathrm{M}_{n 33}$ and $\mathrm{M}_{\mathrm{n} 22}$ are nominal bending strength in major and minor direction.

\section{MODEL DESCRIPTION}

In this study, a 3D finite element model is used to analyse the behaviour of the superstructure of the proposed truss bridge. The model is similar to the configuration of Myintnge bridge (old).The bridge is a four spans continuous steel truss, with a total length of 624 feet with support to support distance of $156 \mathrm{feet}$ each. The width of the bridge is 27 feet with two lanes of traffic.The truss's vertical member are spaced at 26 feet. The truss is $22 \mathrm{feet} \mathrm{high.} \mathrm{The} \mathrm{concrete} \mathrm{deck} \mathrm{thickness} \mathrm{is} 7$ inch. To design the proposed bridge, considered loadings on bridge are dead load, live load, wind load, seismic effect and temperature effect. For vehicle live load, HS20-44 truck of AASHTO Specification is used. ${ }^{[1]}$ AISC-LRFD-93 Specifications ${ }^{[2]}$ is used for design calculation of structural steel members.3D view and elevation view of the proposed bridge model are shown in Figure 1 and Figure 2 respectively.

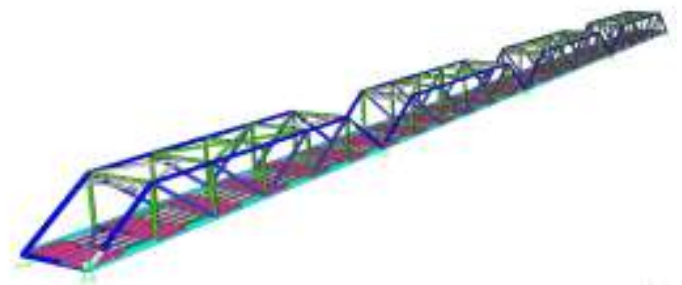

Figure 1.3D view of proposed bridge

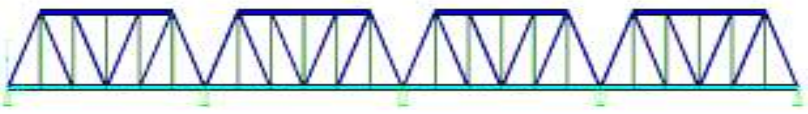

Figure 2.Elevation view of proposed bridge

\subsection{Material Properties}

In this study, the following material strengths were applied in the numerical analysis as shown in Table 1.

Table 1. Strength of materials

\begin{tabular}{|l|l|l|l|}
\hline Materials & $\begin{array}{l}\text { Yield } \\
\text { Strength(ksi) }\end{array}$ & $\begin{array}{l}\text { Ultimate } \\
\text { Strength(ksi) }\end{array}$ & $\begin{array}{l}\text { Poisson's } \\
\text { ratio }\end{array}$ \\
\hline $\begin{array}{l}\text { A572 fteel for } \\
\text { W } \\
\text { section }\end{array}$ & 50 & 65 & 0.3 \\
\hline $\begin{array}{l}\text { BCP325T } \\
\text { steel for } \\
\text { Box } \\
\text { section }\end{array}$ & 64.5 & 88.5 & 0.3 \\
\hline Concrete & - & 4 & 0.02 \\
\hline
\end{tabular}

\subsection{Bridge Geometries}

Bridge geometries of proposed bridge are shown in the following Figures 3,4,5,6.Box shapes are used for upper chord, lower chord, floor beam and diagonal D1members. W shapes are used for vertical, diagonal D2, stringer, diaphragms and upper and lower laterals members. 


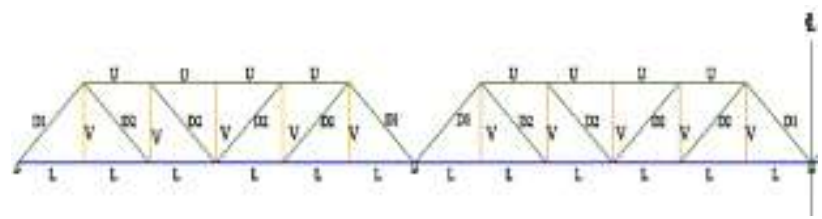

Figure 3.Main Truss

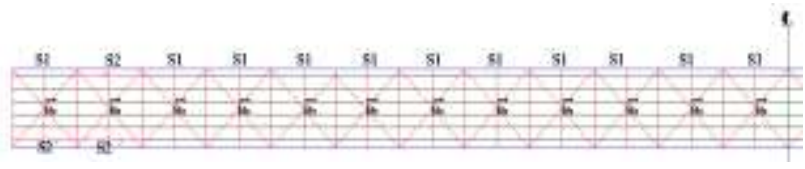

Figure 4.Stringers \& Diaphragms

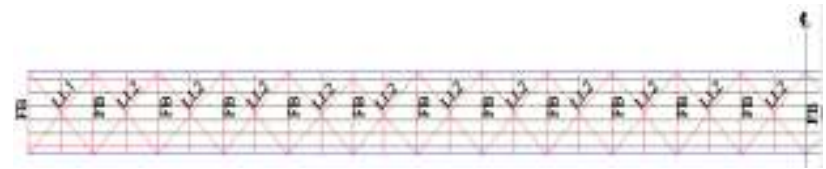

Figure 5. Floor Beams \& Lower Laterals
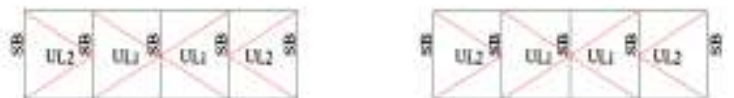

Figure 6. Struts \&Upper Laterals

\section{RESEARCH METHOLOGY}

* Modeling of the proposed bridge with 2D model

* Determination of fracture critical members

\$ Modeling of the proposed bridge with 3D model

* Simulation of intact model and damaged model by removing assumed fracture critical members one at a time

* Identification of redundant or non- redundant bridge and fracture critical members conclusion

\subsection{Fracture Critical Member Determination}

This figure 7 shows the general procedure for fracture critical determination.

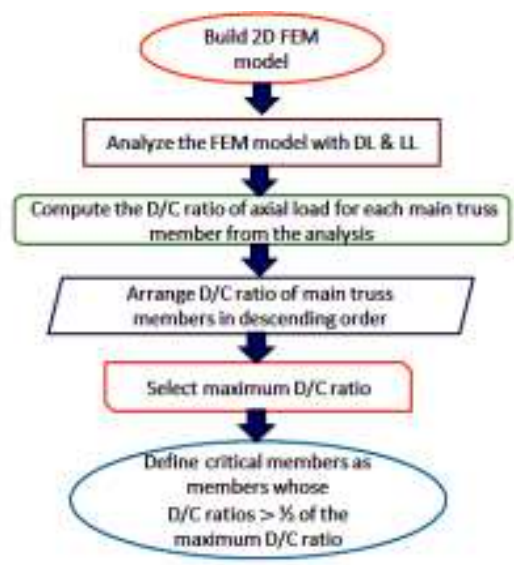

Figure 7.Flow chart of FCM determination 
Figure 8shows demand to capacity ratio of axial load for each main truss member. The configuration of the model and the live load condition is symmetric about the mid span, the critical members were selected for half span of main truss structure as shown in Figure 9 by a thick line.

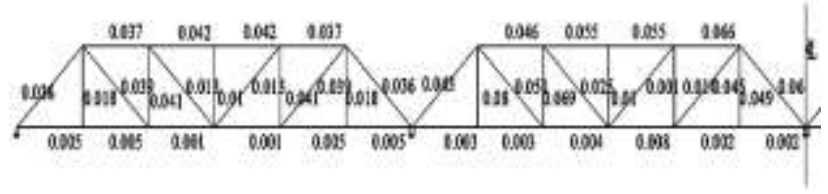

Figure 8. D/C ratios $(R)$ for axial load

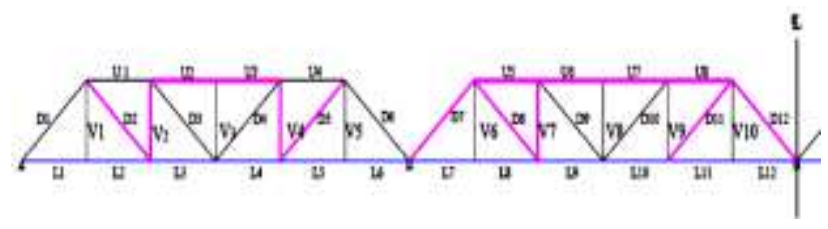

Figure 9. Assumed fracture scenarios in intact bridge

From figure 9,15fracture members were occurred in the proposed bridge. In this study, only 7cases including intact model and diagonal member damaged model were analysed. Figure 10 shows the assumed damaged members for the proposed bridge.

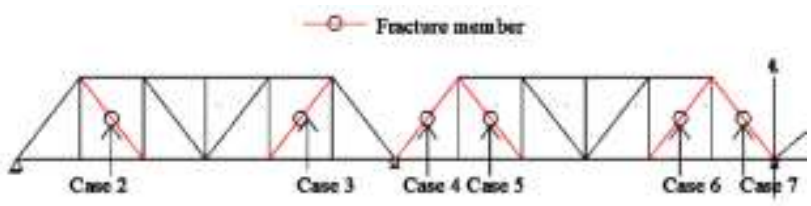

Note . Case 1 is intact model

Figure 10. Member Fracture Scenarios

\subsection{Modeling and Numerical analysis}

Three dimensional (3D) finite element model was built for the proposed bridge. Structural steel members, such as truss members, laterals, and the deck framing system were modelled as frame elements. Shell elements were used to model the reinforced concrete deck. Considered loadings in the linear redundancy analysis are dead load and HS-20 moving live load. Six types of member fracture scenarios are simulated to determine the structural redundancy level of the bridge.

\subsubsection{Analysis results of diagonal member D2 removal (case 2)}

Table 2. Comparison on maximum $D / C$ ratios( $R$ value) near damaged member for case 2 with intact model

\begin{tabular}{|c|c|c|c|c|c|c|c|c|}
\hline \multirow[b]{2}{*}{ 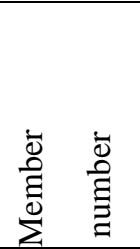 } & \multicolumn{4}{|c|}{$\begin{array}{l}\mathrm{D} / \mathrm{C} \text { ratio in intact model( } \mathrm{R} \\
\text { value })\end{array}$} & \multicolumn{4}{|c|}{$\begin{array}{l}\mathrm{D} / \mathrm{C} \text { ratio in damaged } \\
\text { model( } \mathrm{R} \text { value })\end{array}$} \\
\hline & $\underline{\underline{L}}$ & $\underset{\mathscr{C}}{\overparen{\underline{r}}}$ & 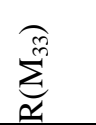 & $\sum_{\underline{\underline{A}}}^{\overparen{A}}$ & $\underline{\underline{L}}$ & $\underset{\widetilde{C}}{\overparen{\underline{r}}}$ & 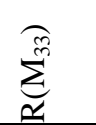 & 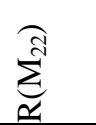 \\
\hline $\begin{array}{l}\text { Upper } \\
\text { chord }\end{array}$ & 0.308 & 0.258 & 0.034 & 0.016 & 0.494 & 0.097 & 0.391 & 0.006 \\
\hline $\begin{array}{l}\text { Lower } \\
\text { chord }\end{array}$ & 0.094 & 0.005 & 0.088 & 0.0 & 0.371 & 0.005 & 0.365 & 0.0 \\
\hline Diagonal & 0.451 & 0.26 & 0.054 & 0.136 & 0.465 & 0.272 & 0.182 & 0.011 \\
\hline Vertical & 0.511 & 0.21 & 0.085 & 0.216 & 1.106 & 0.36 & 0.548 & 0.198 \\
\hline
\end{tabular}




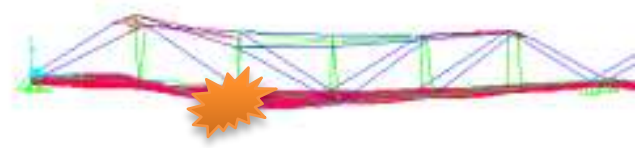

:Location of the member breaking

Figure 11.Deformation diagram

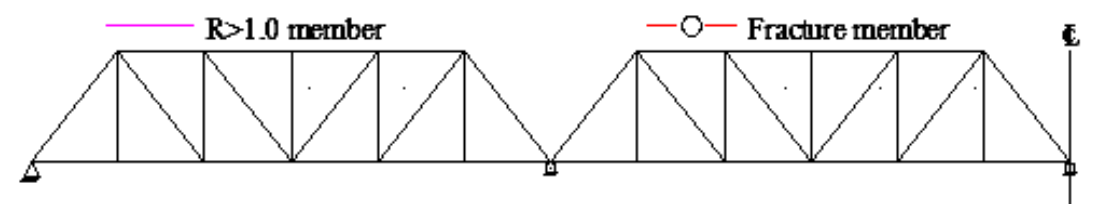

(a) Other truss side of the damaged member

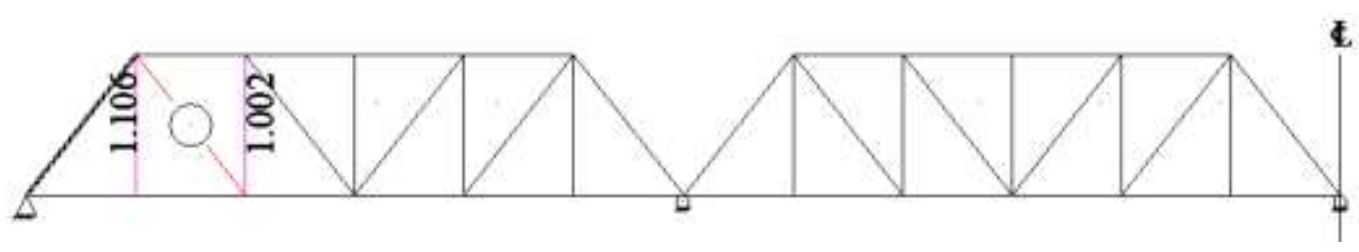

(b)Truss side of the damaged member

Figure 12. D/C ratios( $R$ value $)$ for case 2

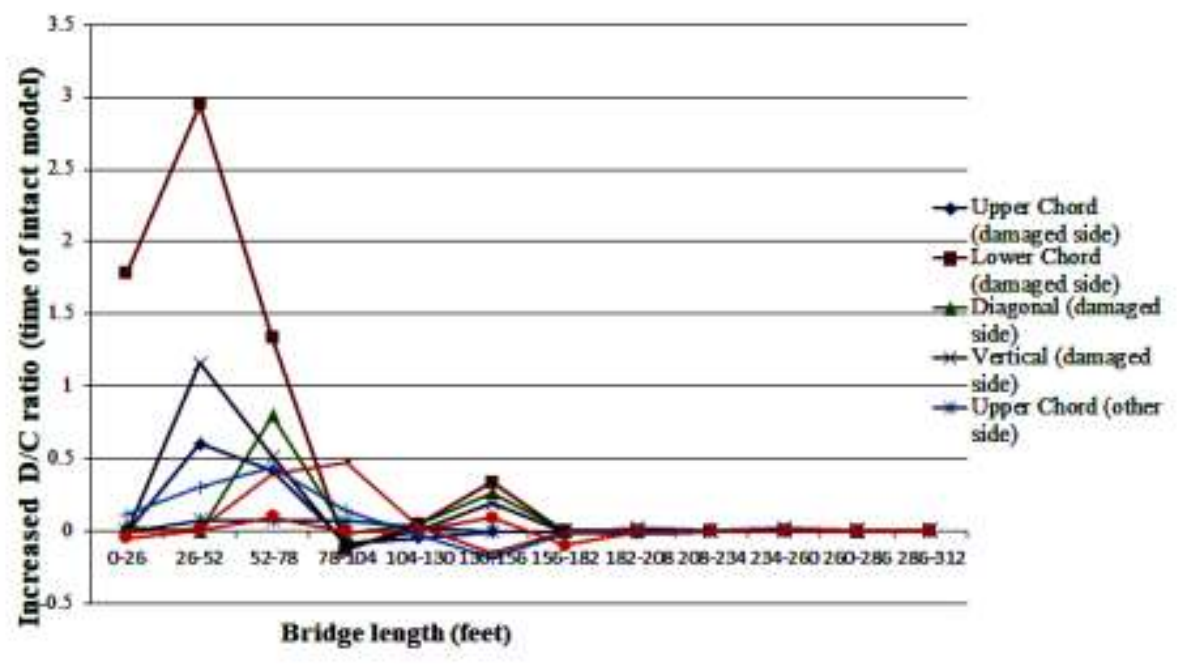

Damage member's location

Figure 13. Comparison on results of increased $D / C$ ratios $(R$ value $)$ due to diagonal $D 2$ removal

An analysis of a diagonal truss member removal at the truss bridge is shown in Figure11 to 13.Although, the truss side of the member was breaking to deform greatly(-1.375in), the other side of the breaking(-0.43in) did not deform as much.Figure 12 shows the calculation result for $\mathrm{D} / \mathrm{C}$ ratios of truss members, The $\mathrm{D} / \mathrm{C}$ ratios of vertical members near the damaged diagonal member is greater than1.0. The largest value is 1.106 on the truss side of the member removal. The $\mathrm{D} / \mathrm{C}$ ratios in other truss side do no greater than 1.0.

From figure13,the increase in D/C ratios of all main truss members near the damaged member is higher than away from the damaged member. The $\mathrm{D} / \mathrm{C}$ ratio of lower chord member near member removal in damaged side increases 2.9 times of the value of intact member. 
International Journal of Engineering Research And Advanced Technology, Vol.5, Issue 8, August-2019

4.2.2 Analysis results of diagonal member D5 removal (case 3)

Table 3. Comparison on maximum $D / C$ ratios( $R$ value) near damaged member for case 3 with intact model

\begin{tabular}{|c|c|c|c|c|c|c|c|c|}
\hline \multirow[b]{2}{*}{ 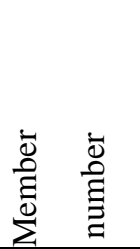 } & \multicolumn{4}{|c|}{$\begin{array}{l}\mathrm{D} / \mathrm{C} \text { ratio in intact model }(\mathrm{R} \\
\text { value })\end{array}$} & \multicolumn{4}{|c|}{$\begin{array}{l}\mathrm{D} / \mathrm{C} \text { ratio in damaged } \\
\text { model( } \mathrm{R} \text { value })\end{array}$} \\
\hline & $\underline{\underline{1}}$ & $\underset{\widetilde{E}}{\overparen{\underline{\varepsilon}}}$ & $\sum_{\widetilde{N}}^{\infty}$ & $\sum_{\underline{\pi}}^{\text {}}$ & $\underline{\underline{1}}$ & $\underset{\widetilde{E}}{\overparen{\underline{q}}}$ & $\sum_{\underline{\pi}}^{\infty}$ & 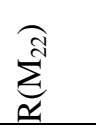 \\
\hline $\begin{array}{l}\text { Upper } \\
\text { chord }\end{array}$ & 0.296 & 0.256 & 0.027 & 0.014 & 0.507 & 0.099 & 0.404 & 0.005 \\
\hline $\begin{array}{l}\text { Lower } \\
\text { chord }\end{array}$ & 0.101 & 0.005 & 0.095 & 0.0 & 0.384 & 0.005 & 0.378 & 0.0 \\
\hline Diagonal & 0.427 & 0.248 & 0.052 & 0.126 & 0.478 & 0.276 & 0.19 & 0.012 \\
\hline Vertical & 0.463 & 0.091 & 0.128 & 0.224 & 1.122 & 0.361 & 0.563 & 0.198 \\
\hline & & 0.1 .0 nem & & & - Fract & menber & & \\
\hline
\end{tabular}

(a)Other truss side of the damaged member

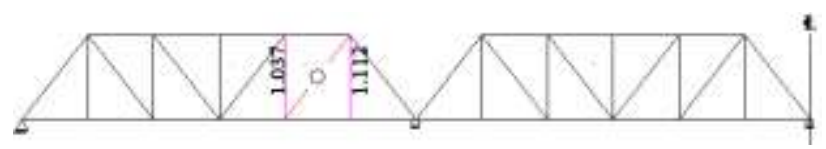

(b) Truss side of the damaged member

Figure 14. $D / C$ ratios( $R$ value $)$ for case 3

From the analysis of a diagonal truss member D5 removal case, the D/C ratios of vertical members and one upper lateral member near the damaged member are exceeding 1.0.Maximum $\mathrm{D} / \mathrm{C}$ ratios for damaged model and intact model are compaired in table 3. Changes in $\mathrm{D} / \mathrm{C}$ ratio is high in vertical member .

\subsubsection{Analysis results of diagonal memberD7,D12 removal(case 4,7)}

Table 4. Comparison on maximumD/C ratios( $R$ value)near damaged member for case 4 and case 7 with intact model

\begin{tabular}{|c|c|c|c|c|c|c|c|c|}
\hline \multirow[b]{2}{*}{ 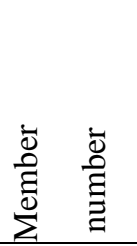 } & \multicolumn{4}{|c|}{$\begin{array}{l}\mathrm{D} / \mathrm{C} \text { ratio in intact model }(\mathrm{R} \\
\text { value })\end{array}$} & \multicolumn{4}{|c|}{$\begin{array}{l}\mathrm{D} / \mathrm{C} \text { ratio in damaged } \\
\text { model( } \mathrm{R} \text { value })\end{array}$} \\
\hline & $\simeq$ & 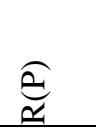 & $\sum_{\Sigma=}^{\infty}$ & 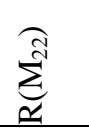 & $\mathscr{L}$ & $\underset{\widetilde{f}}{\overparen{f}}$ & $\sum_{\Sigma=}^{\infty}$ & 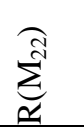 \\
\hline $\begin{array}{l}\text { Upper } \\
\text { chord }\end{array}$ & 0.292 & 0.252 & 0.026 & 0.014 & 0.365 & 0.292 & 0.036 & 0.037 \\
\hline $\begin{array}{l}\text { Lower } \\
\text { chord }\end{array}$ & 0.142 & 0.008 & 0.131 & 0.003 & 0.685 & 0.019 & 0.649 & 0.017 \\
\hline Diagonal & 0.424 & 0.246 & 0.052 & 0.127 & 0.746 & 0.326 & 0.007 & 0.413 \\
\hline Vertical & 0.466 & 0.091 & 0.127 & 0.248 & 2.005 & 0.87 & 0.686 & 0.449 \\
\hline
\end{tabular}

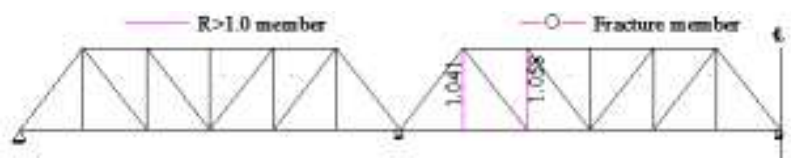

(a) Other truss side of the damaged member for case4 


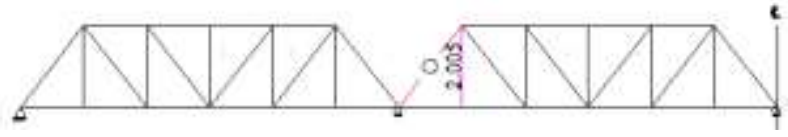

(b) Truss side of the damaged member for case 4

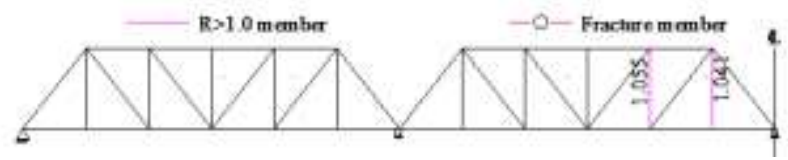

(c) Other truss side of the damaged member for case 7

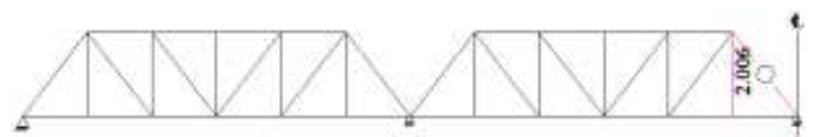

(d)Truss side of the damaged member for case7

Fig 15.D/C ratios(R value)for case 4,7

Figure 15 shows the calculation result for D/C ratios of truss members for case4,7 .It is greatly exceeds 1 when it reaches near the damaged member at the damaged and at the other side of the truss. D/C ratios in upper laterals away from damaged member also exceeds 1.The maximum value of $\mathrm{D} / \mathrm{C}$ ratio in damaged side is 2.006 and in other side is 1.055 .

\subsubsection{Analysis results of diagonal member D8,D11 removal(case 5,6)}

Table 5. Comparison on maximum $D / C$ ratios ( $R$ value) near damaged member for case 5 and case 6 with intact model

\begin{tabular}{|c|c|c|c|c|c|c|c|c|}
\hline \multirow[b]{2}{*}{ 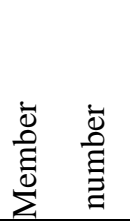 } & \multicolumn{4}{|c|}{$\begin{array}{l}\mathrm{D} / \mathrm{C} \text { ratio in intact model }(\mathrm{R} \\
\text { value })\end{array}$} & \multicolumn{4}{|c|}{$\begin{array}{l}\mathrm{D} / \mathrm{C} \text { ratio in damaged } \\
\text { model( } \mathrm{R} \text { value })\end{array}$} \\
\hline & & & $\sum_{\approx=}^{\infty}$ & 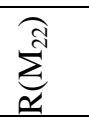 & $\underline{\simeq}$ & & $\sum_{\underline{\alpha}}^{\infty}$ & $\sum_{\underline{I}}^{I}$ \\
\hline $\begin{array}{l}\text { Upper } \\
\text { chord }\end{array}$ & 0.292 & 0.252 & 0.026 & 0.014 & 0.495 & 0.097 & 0.393 & 0.005 \\
\hline $\begin{array}{l}\text { Lower } \\
\text { chord }\end{array}$ & 0.102 & 0.006 & 0.096 & 0.00 & 0.374 & 0.005 & 0.368 & 0.0 \\
\hline Diagonal & 0.452 & 0.288 & 0.047 & 0.116 & 0.586 & 0.335 & 0.049 & 0.201 \\
\hline Vertical & 0.466 & 0.091 & 0.127 & 0.248 & 1.104 & 0.355 & 0.549 & 0.2 \\
\hline
\end{tabular}

(a) Other truss side of the damaged member for case 5,6

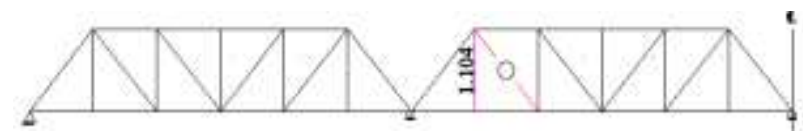

(b) Truss side of the damaged member for case 5

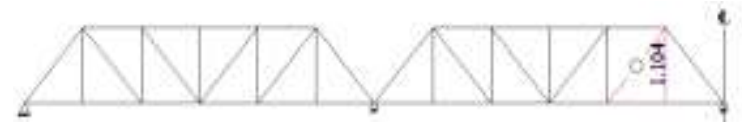

(c) Truss side of the damaged member for case 6

Figure 16. D/C ratios( $R$ value)for case 5,6

From the analysis of diagonal members D8,D11 removal cases,only one member is found which D/C ratio is higher than 1.This removal case effect the $\mathrm{D} / \mathrm{C}$ ratios in other side members because of alternate load path.Maximum $\mathrm{D} / \mathrm{C}$ ratio in damaged side is 1.104 for both cases. 
International Journal of Engineering Research And Advanced Technology, Vol.5, Issue 8, August-2019

Table 6. Number of ultimate members and maximum $D / C$ ratio( $R$ value)

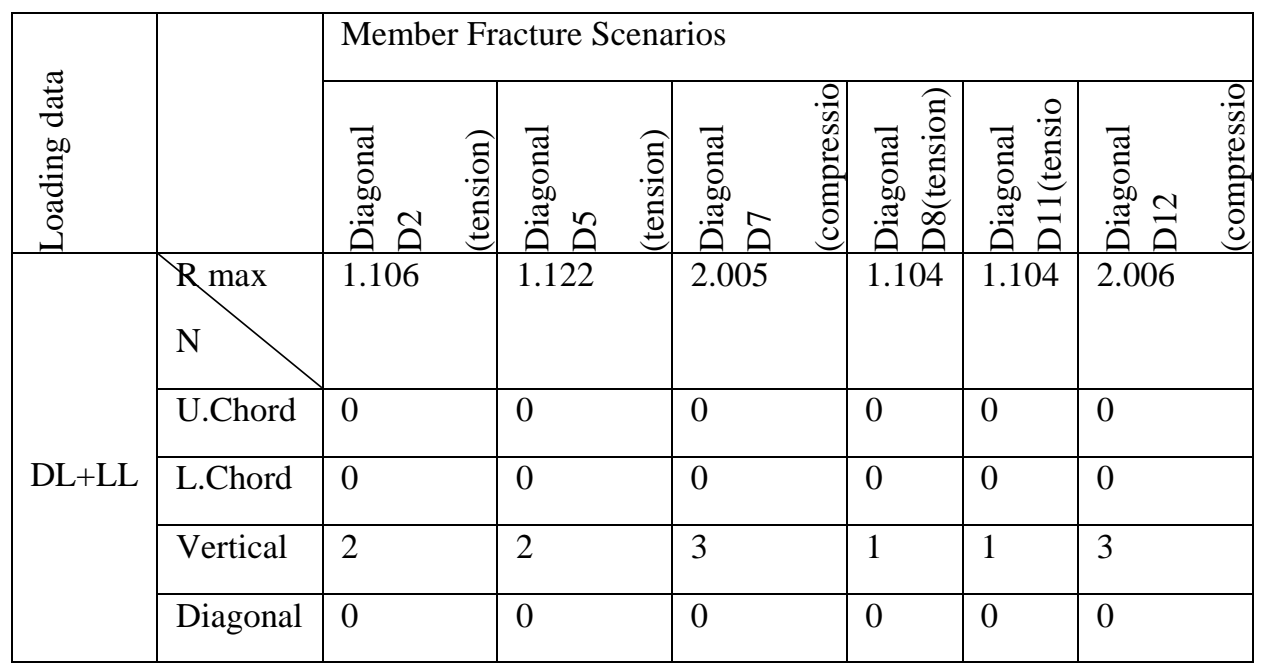

Comparison on results of maximum D/C ratios near damaged member for case 2, 3,4,5,6 and 7 with intact model are shown in Table 2,3,4and 5.In an intact bridge, axial force for upper chord is a dominant factor but in damaged bridge, major bending moment serves as a dominant factor.For lower chord, major moment is a control loading in both intact and damage bridges.

\section{CONCLUSIONS}

In this study, four spans continuous steel truss bridge is analyzed and designed by SAP 2000 Software. Redundancy analysis of proposed bridge is done by defining critical members. In this paper,analysis of diagonal truss member removal cases at the truss bridge is carried out.In linear redundancy analysis, the effect of member removal is highest near the damaged member. Case 4 and case 7 are most dangerous cases because it holds the largest value in $R_{\max }$ and number of ultimate failure members. In all cases of diagonal damaged models, the influence of damage is significantly great for vertical members near the fracture scenarios. The influence of member removal is great when the truss diagonal member is near the support. Although the $\mathrm{D} / \mathrm{C}$ ratios ( $\mathrm{R}$ value) in damaged side increase greatly due to $\mathrm{D} 2$ removal, the $\mathrm{D} / \mathrm{C}$ ratios( $\mathrm{R}$ value) in other side do not as much.From analysis results, the maximum $\mathrm{R}$ values in all cases are greater than 1.The collapse of the bridge can be found when these members are damaged. Therefore, careful maintenance and inspection should be made to the diagonal members because these members are fracture critical members in truss bridges.

\section{ACKNOWLEDGEMENT}

The author would like to express grateful thanks to Ministry of Construction for permission of drawing data.

\section{REFERENCES}

[1] American Association of State Highway and Transportation Officials Washington.D.C.2012, "AASHTO LRFD Bridge Design Specifications

[2] American Institute of Steel Construction,Chicago,III,1994,"Manual of Steel Construction, Load and Resistance Factor Design, $2^{\text {nd }}$ Edition"

[3] Ghosn,M.andMoses,F.,(1998) “ Redundancy in Highway Bridge Superstructures ”,National Cooperative Highway Research Program NCHRP 406, Washington,DC

[4] Okui, Y., Nagatani, H., Akashi, N., Matsuda, T., Obata, M. Y. Y., Ishii, H., Miyamori, M., and Hirayama, H. (2010). "After Fracture Redundancy Analysis of Steel Truss Bridges in Japan." IABSE-JSCE Joint Conference on Advances in Bridge Engineering-II 